\title{
DESENVOLVIMENTO E APLICAÇÃO DE MÉTODOS PARA A DETERMINAÇÃO DE IVERMECTINA EM MEDICAMENTOS DE USO VETERINÁRIO
}

\author{
Fabio Macedo da Costa e Annibal Duarte Pereira Netto* \\ Departamento de Química Analítica, Instituto de Química, Universidade Federal Fluminense, Outeiro de São João Batista, s/n, \\ 24020-141 Niterói - RJ, Brasil
}

Recebido em 5/6/11; aceito em 26/8/11; publicado na web em 30/9/11

\begin{abstract}
DEVELOPMENT AND APPLICATION OF METHODS FOR THE DETERMINATION OF IVERMECTIN IN VETERINARIAN MEDICATIONS. Two methods for the determination of Ivermectin in veterinarian medications were developed and compared. One of the methods was based on UV spectrometry and the other on HPLC-UV. The former method was shown to be positively biased regarding the nominal concentrations of Ivermectin in different medications. The method of standard addition was unable to correct this bias, indicating significant matrix effects. The HPLC-UV method showed good linearity, throughput, recovery and limits of detection and quantitation adequate for its application in the evaluation of Ivermectin in medications. Several medications were evaluated and good agreement between our results and their nominal concentrations was found.
\end{abstract}

Keywords: Ivermectin; HPLC-UV; absorption spectrometry.

\section{INTRODUÇÃO}

A produção de alimentos de origem animal tem cada vez maior demanda devido ao alto valor biológico destes produtos. O Brasil é um dos principais fornecedores mundiais deste tipo de alimentos e o aumento na produtividade com garantia da segurança alimentar, tanto química como microbiológica, é uma das metas da produção agropecuária nacional. Neste cenário, a criação intensiva de aves e suínos para corte e de bovinos, tanto para corte quanto para a produção de leite, cresceu e a produção animal tornou-se mais eficiente, utilizando áreas cada vez menores. Como consequência, a aglomeração de animais tornou-se maior e a ocorrência de infecções, ectoparasitoses (infestações por carrapatos, berne, sarnas etc) e verminoses é uma preocupação constante. Assim, o regime de criação intensiva implica no uso de drogas veterinárias, principalmente fármacos com atividades antimicrobiana e antiparasitária, que passaram a ser consideradas insumos para a produção e destacam-se como as classes de maior faturamento da indústria farmacêutica veterinária.

O uso de drogas preventivas e/ou terapêuticas é condição sine qua non para coibir doenças que interferiram na qualidade do produto final e no prazo esperado pela indústria agropecuária. Neste escopo, medicamentos com características antibióticas, quimioterápicas, antihelmínticas (endoparasiticidas), ectoparasiticidas e endectoparasiticidas (substâncias com propriedades de endo- e ectoparasiticidas) são usados. A grande demanda por produtos farmacêuticos veterinários no Brasil pode ser verificada considerando-se o expressivo número de indústrias voltadas à produção destes produtos instaladas no país, principalmente no estado de São Paulo. Dentre os diversos produtos farmacêuticos produzidos, destacam-se os antimicrobianos, os parasiticidas e os desinfetantes. A criação de diferentes classes de animais tem relevante papel neste mercado (Tabelas 1 e 2 ). ${ }^{1}$

Em 1975 foi descoberto um novo grupo de substâncias químicas, o das lactonas macrocíclicas, que compreende as avermectinas e milbemicinas. Esse grupo de substâncias causou grande impacto na criação de animais para exploração agropecuária, pois apresenta elevada eficácia parasiticida contra artrópodes e nematódeos e é efetivo em diversas espécies de animais. O grupo das avermecti-

*e-mail: annibal@vm.uff.br
Tabela 1. Valores envolvidos no mercado de medicamentos veterinários no Brasil por classe de fármacos

\begin{tabular}{lc}
\hline Classe terapêutica & Valores $(\mathrm{R} \$)$ \\
\hline Antimicrobianos & $633.417 .717,00$ \\
Antiparasitários & $960.983 .211,00$ \\
Biológicos & $825.734 .942,00$ \\
Outros & $404.547 .819,00$ \\
\hline
\end{tabular}

Tabela 2. Valores envolvidos no mercado de medicamentos veterinários no Brasil por tipo de animais

\begin{tabular}{lc}
\hline Espécies & Valores $(\mathrm{R} \$)$ \\
\hline Ruminantes & $1.564 .344 .045,00$ \\
Suínos & $431.223 .365,00$ \\
Aves & $401.921 .842,00$ \\
Animais Domésticos & $292.633 .855,00$ \\
Equinos & $77.848 .383,00$ \\
Outros & $56.712 .199,00$ \\
\hline
\end{tabular}

Ref. 8 - Ano base: 2009

nas $(\mathrm{a}=$ sem + verm $=$ verme + ect $=$ ectoparasita + in $=$ produto farmacêutico), produzido pela fermentação do fungo Streptomyces avemitilis, é constituído pela Ivermectina, Abamectina, Doramectina, Eprinomectina e Selamectina, tem comportamento farmacocinético que depende da via de administração, da formulação, da condição corpórea e da espécie animal à qual é destinada, ${ }^{2}$ além de sua concentração e tempo de exposição ao parasito. Estas substâncias são eficazes e têm custos relativamente baixos. ${ }^{3}$

A Ivermectina é sintetizada a partir da avermectina e é constituída por uma mistura de homólogos que não deve conter menos que $80 \%$ de seu homólogo B1a (5-O-dimetil-22,23-di-hidroavermectina $\mathrm{A}_{1 \mathrm{a}}$ ), que tem fórmula molecular $\mathrm{C}_{48} \mathrm{H}_{74} \mathrm{O}_{14}$ e massa molecular de $875.1 \mathrm{~g} / \mathrm{mol}$ (Figura 1a) e não mais de $20 \%$ de seu homólogo B1b (5-O-dimetil-25-(1-metilpropil)-22,23-di-hidro-25-(1-metil-etil) avermectina $\mathrm{A}_{1 \mathrm{a}}$ ), de fórmula molecular $\mathrm{C}_{47} \mathrm{H}_{72} \mathrm{O}_{14}$ e massa molecular $861.07 \mathrm{~g} / \mathrm{mol}$ (Figura 1b). ${ }^{4}$ 

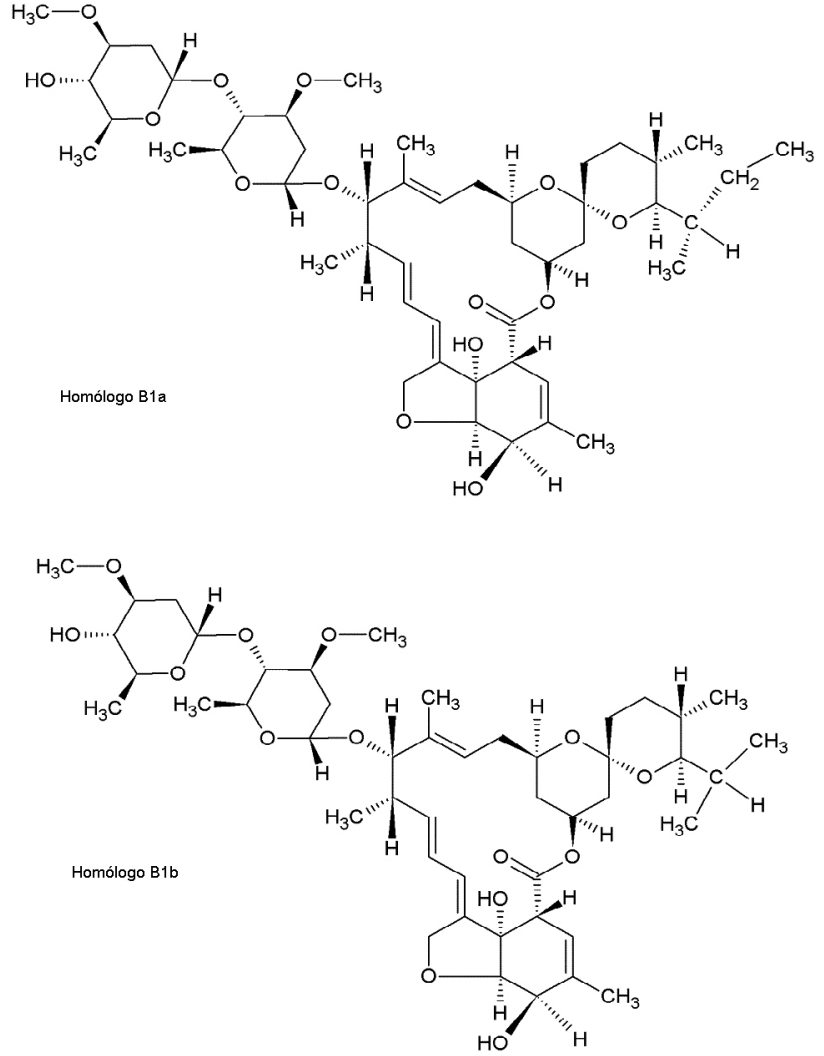

Figura 1. Estruturas químicas das substâncias homólogas que podem compor a Ivermectina

Pequenas diferenças nas formulações e composições dos medicamentos veterinários podem causar alterações em sua eficácia. Dessa forma, um método prático e de baixo custo, que seja capaz de ser aplicado de forma simplificada, para determinação e controle de qualidade deste princípio ativo (Ivermectina) tão usado pela indústria agropecuária no Brasil, é bastante útil para que as terapêuticas empregadas de fato utilizem a quantidade de fármaco necessária, evitando sub-dosagens, que podem conduzir à resistência dos parasitos e falha no tratamento ou, de outra forma, doses altas que implicam em maiores possibilidades de resíduos nos derivados (carne e leite) utilizados como alimentos, além dos resíduos ambientais, devido à excreção fecal ou pelo leite deste fármaco. ${ }^{4-7}$ Assim, estudos que avaliem a qualidade do produto, principalmente a concentração de princípio ativo nas preparações e sua conformidade com o especificado, são fundamentais. É interessante considerar que neste momento está em estudo a produção de medicamentos veterinários genéricos, o que tornará ainda mais importante o controle de qualidade e avaliação destes medicamentos.

Com foco na grande demanda dos vários produtos à base de Ivermectina encontrados no comércio, este trabalho buscou desenvolver e implementar um método rápido para controle de qualidade, que tenha poucas ou nenhuma etapa de tratamento de amostras, capaz de quantificar Ivermectina nas formulações farmacêutico-veterinárias disponíveis no mercado.

Com esta finalidade, dois métodos de determinação de Ivermectina foram desenvolvidos e avaliados. Um deles baseia-se em espectrofotometria de absorção no UV e o outro em cromatografia líquida de alta eficiência com detecção no UV (CLAE-UV). A técnica de espectrofotometria de absorção foi inicialmente escolhida, pois permite maior facilidade de operação, menor custo, maior produtividade e menor geração de resíduos. Entretanto, os resultados obtidos na sequência do trabalho indicaram a necessidade do uso de CLAE-
UV para a determinação. Os resultados obtidos pelos dois métodos foram avaliados e comparados entre si.

\section{PARTE EXPERIMENTAL}

\section{Reagentes e solventes}

Ivermectina foi adquirida da Sigma (MO, EUA). Sua pureza ( $\geq 98 \%)$ e a concentração do homólogo B1b $(\leq 2 \%)$ foram avaliadas por injeção direta em sistema de CLAE acoplado à espectrometria de massas através de interface de eletronebulização. Acetonitrila, metanol, hexano e isopropanol grau HPLC foram adquiridos da Tedia Brasil. Água ultrapurificada foi preparada através de um sistema de Simplicity (Millipore, EUA) após a destilação.

\section{Determinação de Ivermectina por espectrofotometria de absorção}

Um espectrofotômetro 800 XI Femto (Femto, Brasil) e cubetas de quartzo foram usadas para a obtenção de espectros de absorção e na determinação espectrofotométrica de Ivermectina. Curvas analíticas foram construídas com soluções de concentrações de 0,50 ; 1,$00 ; 2,00 ; 5,00 ; 10,0 ; 20,0 ; 25,0 ; 40,0$ e $50,0 \mathrm{mg} \mathrm{L}^{-1}$, em triplicatas independentes, a partir de diluição da solução estoque. A cada dia de trabalho uma curva analítica era construída e, caso o tempo de análise ultrapassasse $4 \mathrm{~h}$, nova série de diluições era realizada e outra curva construída.

Determinação de Ivermectina por cromatografia líquida de
alta eficiência com detecção por UV-DAD (HPLC-UV-DAD)

O sistema de HPLC consistiu de uma bomba binária, um desgaseificador, um injetor automático, um compartimento coluna e um detector UV-DAD (Agilent Série 1100, EUA) controlado por uma estação de trabalho Agilent. Os comprimentos de onda para detecção foram selecionados a partir dos espectros de absorção. Uma coluna Zorbax Eclipse XDB $\mathrm{C}_{8}(150$ x 4,6 mm; $5 \mu \mathrm{m}$, Agilent, EUA) foi empregada. As condições cromatográficas (composição da fase móvel, vazão, temperatura e volume de injeção) foram avaliadas considerando o formato do pico cromatográfico e o tempo de retenção. As melhores condições de separação foram obtidas a $35^{\circ} \mathrm{C}$ com um gradiente de metanol e água, que variava de metanol/água (50:50) em tempo igual a zero até uma proporção de metanol/água (100:0) em 10 min, e reequilíbrio nas condições iniciais até 12 min. Foram empregados tempo de equilíbrio de 1 min entre injeções sucessivas, vazão constante $\left(1,5 \mathrm{~mL} \mathrm{~min}^{-1}\right)$ e volume injetado de $20 \mathrm{~mL}$.

Para análise quantitativa, as curvas analíticas foram obtidas com padrões de concentrações de 0,$50 ; 1,00 ; 2,00 ; 5,00 ; 10,0 ; 20,0$ mg $\mathrm{L}^{-1}$, sempre em triplicatas independentes.

\section{Descrição das amostras}

Medicamentos injetáveis, de uso exclusivamente veterinário, contendo solução oleosa de Ivermectina a $1 \%$ foram estudados. Estas preparações são as mais comumente encontradas em estabelecimentos especializados, pois são produzidas, nesta concentração, por diversos laboratórios farmacêutico-veterinários. ${ }^{8}$ Algumas formulações injetáveis são identificadas com as iniciais L.A., indicando que o medicamento tem longa ação. Neste caso, em geral, são preparações muito oleosas, que implicam em absorção mais lenta a partir do local de aplicação e, portanto, prolongam a meia-vida e o tempo de ação do princípio ativo no organismo animal.

As preparações contendo Ivermectina geralmente contêm apenas 
este princípio ativo na formulação, diferente do que ocorre com outros vermífugos que, muitas vezes, se encontram associados a mais de um princípio ativo com atividade anti-helmíntica. Entretanto, alguns laboratórios comercializam preparações contendo Ivermectina associada às vitaminas lipossolúveis A, D3 e E e, em certos casos, a outra substância quimicamente relacionada como, por exemplo, a Abamectina, que também tem atividade endectocida.

\section{Frascos multidose}

Frascos multidose, confeccionados em material plástico, contendo $50 \mathrm{~mL}$ de solução oleosa de Ivermectina a $1 \%$, fabricados por quatro laboratórios distintos, foram adquiridos em diferentes bairros da região Metropolitana do Rio de Janeiro, na Região Oceânica de Niterói e no município de Nova Friburgo.

\section{Ampolas}

Ampolas de vidro, contendo $1 \mathrm{~mL}$ de solução oleosa de Ivermectina a $1 \%$, fabricadas por outros quatro laboratórios distintos dos fabricantes de frascos multidose, foram adquiridas em estabelecimentos comerciais localizados em diferentes bairros da região Metropolitana do Rio de Janeiro e na Região Oceânica de Niterói. Estas formulações têm aplicação principal em animais domésticos como, por exemplo, cães, embora sejam aplicadas em menor extensão em gado, devido a seu maior custo relativo.

\section{Diluição das preparações farmacêuticas}

As amostras estudadas tinham concentração relativamente elevada (da ordem de $1 \%$ ou $10.000 \mathrm{mg} \mathrm{L}^{-1}$ ) e fora das faixas lineares dos métodos desenvolvidos. Para a diluição das amostras, um procedimento em duas etapas foi adotado, levando a uma diluição de 1.000 vezes (de 10.000 para cerca de $10,00 \mathrm{mg} \mathrm{L}^{-1}$ ) de Ivermectina.

Com esta finalidade, alíquotas de $100 \mu \mathrm{L}$ das amostras de medicamentos foram transferidas para balões volumétricos de $10,0 \mathrm{~mL}$. Após adição de cerca de $5 \mathrm{~mL}$ de metanol ou acetonitrila, a solução era homogeneizada em vórtex e, em seguida, o volume era completado e a solução novamente agitada em vórtex. Uma alíquota de $1,00 \mathrm{~mL}$ desta solução era transferida para outro balão volumétrico de 10,0 $\mathrm{mL}$ e diluída com metanol ou acetonitrila.

A retirada de alíquotas das soluções oleosas das formulações levava à retenção e perda de parte do volume de amostra nas ponteiras das pipetas automáticas. Para minimizar esta perda, foi usada uma seringa de vidro de cromatografia líquida $(250 \mu \mathrm{L})$, que permitia a transferência da alíquota de $100 \mu \mathrm{L}$ de amostra para o balão volumétrico, sem retenção de solução na agulha ou na parede da seringa.

Para avaliar analiticamente o que era observado visualmente, foram preparadas soluções a partir da diluição de um mesmo medicamento, tomando-se alíquotas de $100 \mu \mathrm{L}$ com a pipeta automática e ponteira e com a seringa de vidro. Os espectros de absorção destas soluções foram comparados e a porcentagem de perda foi estimada pela razão dos sinais nos máximos de absorção.

\section{Preparações farmacêuticas de longa ação (L.A.)}

Não foi possível fazer a diluição de duas preparações de L.A. da forma descrita acima, já que as alíquotas de $100 \mu \mathrm{L}$ não eram miscíveis em metanol ou acetonitrila. Misturas com diferentes proporções de isopropanol e metanol foram avaliadas na dissolução destes medicamentos. O menor volume possível de isopropanol foi usado e as duas amostras precisaram de diferentes volumes dos alcoóis para sua diluição. Os espectros de absorção (contra o ar) das misturas de metanol e isopropanol, usadas para solubilizar as amostras dos dois frascos citados, foram avaliados para verificar a interferência do isopropanol na determinação espectrofotométrica da Ivermectina.

\section{Determinação do comprimento de onda de máxima absorção $\left(\lambda_{\text {máx }}\right)$ da Ivermectina}

A solubilidade da Ivermectina sólida foi avaliada em diferentes solventes (água, metanol, acetonitrila e hexano). Em metanol e em acetonitrila ocorreu rápida solubilização do sólido na temperatura do laboratório $\left(25^{\circ} \mathrm{C}\right)$.

Soluções estoque de Ivermectina $\left(100 \mathrm{mg} \mathrm{L}^{-1}\right)$ foram preparadas por dissolução de 5,00 mg de padrão sólido em 50,0 mL de metanol ou acetonitrila. De cada uma destas soluções foram retiradas 5 alíquotas de 1,00 mL, que foram diluídas independentemente para $10,0 \mathrm{~mL}$, com metanol ou acetonitrila, levando à concentração de $10,0 \mathrm{mg} \mathrm{L}^{-1}$.

Os espectros de absorção destas soluções foram obtidos entre os comprimentos de onda de 190 a 800 nm, com intervalo de 1 nm. Foram usadas cubetas de quartzo e o solvente empregado na dissolução do sólido foi usado como referência.

\section{RESULTADOS E DISCUSSÃO}

\section{Implementação de método para determinação espectrofotométrica de Ivermectina}

Este método foi escolhido inicialmente já que permite pouca manipulação de amostras, tem custo menor e produtividade relativamente maior quando comparado aos métodos cromatográficos.

\section{Determinação do comprimento de onda de máxima absorção $\left(\lambda_{\text {máx }}\right)$ da Ivermectina}

Os espectros de absorção de soluções de Ivermectina $\left(100 \mathrm{mg} \mathrm{L}^{-1}\right)$ em metanol e acetonitrila foram praticamente iguais, com máximo de absorção em $246 \mathrm{~nm}$ e máximos relativos em 238 e $254 \mathrm{~nm}$. O espectro de absorção da Ivermectina entre 200 e $280 \mathrm{~nm}$ em metanol, é apresentado na Figura 2. O comprimento de onda de $246 \mathrm{~nm}$ foi escolhido para a determinação espectrofotométrica por apresentar maior absorvância, embora os comprimentos de onda correspondentes aos outros máximos relativos $(238,254$ ou $260 \mathrm{~nm})$ tenham sido usados previamente na determinação de Ivermectina em alimentos. ${ }^{9-11}$ Metanol foi usado como solvente na sequência do trabalho, devido ao seu menor custo em relação ao da acetonitrila no momento da execução deste estudo.

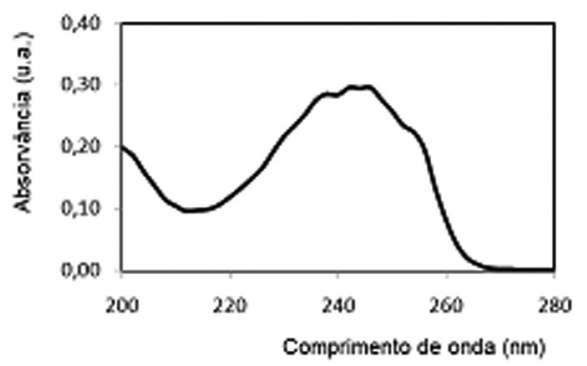

Figura 2. Espectro de absorção de solução de Ivemectina $\left(100 \mathrm{mg} \mathrm{L}^{-1}\right)$ em metano, entre 200 e $280 \mathrm{~nm}$

As características oleosas da matriz das soluções estudadas levaram à avaliação das condições de preparação das soluções. Com esta finalidade, soluções contendo cerca de $10 \mathrm{mg} \mathrm{L}^{-1}$ de Ivermectina em 
metanol e acetonitrila foram preparadas a partir de diluição de alíquotas de $100 \mu \mathrm{L}$ do medicamento $\mathrm{E}$, tomadas com a pipeta automática e ponteira e com a seringa de vidro. Os espectros de absorção (200 a $280 \mathrm{~nm}$ ) destas soluções foram obtidos e as absorvâncias das soluções obtidas em cada solvente foram comparadas nos comprimentos de onda máximos de absorção (Tabela 3).

Tabela 3. Absorvâncias de soluções contendo cerca de $10 \mathrm{mg} \mathrm{L}^{-1}$ de Ivermectina, preparadas a partir de diluição com pipeta automática e seringa de vidro do medicamento $\mathrm{E}$, em 4 comprimentos de onda máximos da Ivermectina

\begin{tabular}{lcccc}
\hline & \multicolumn{5}{c}{ Absorvâncias (u.a.) } \\
\hline Comprimentos de onda (nm) & 238 & 246 & 254 & 260 \\
Pipeta e ponteira & 0,357 & 0,398 & 0,293 & 0,153 \\
Seringa de vidro & 0,398 & 0,441 & 0,324 & 0,164 \\
Aumento de sinal & 11,5 & 10,8 & 10,6 & 7,2 \\
\hline
\end{tabular}

A absorvância da solução preparada a partir de diluição com seringa de vidro foi cerca de $10 \%$ maior em todos os comprimentos de onda avaliados, exceto em $260 \mathrm{~nm}(7,2 \%)$, que a absorvância da solução preparada a partir da pipeta automática, confirmando a observação de que parte da solução se aderia à ponteira de plástico. Resultados semelhantes foram observados com outros medicamentos e, em todos os casos, os máximos de absorção dos espectros ocorreram em $246 \mathrm{~nm}$. A seringa de vidro passou então a ser usada na diluição inicial dos medicamentos.

A diluição dos medicamentos de longa ação envolveu o uso de mistura de isopropanol e metanol. Os medicamentos $\mathrm{G}$ e $\mathrm{F}$ foram diluídos para 10,0 mL com misturas contendo, respectivamente, 3,0 e 4,0 mL de isopropanol em metanol. Os espectros de absorção destas misturas de alcoóis usando ar como referência não apresentaram nenhuma absorção no comprimento de onda empregado na determinação da Ivermectina (246 nm), indicando que, como esperado, não havia interferência do isopropanol na determinação.

As absorvâncias de uma série de soluções-padrão de Ivermectina foram medidas em triplicatas independentes. Coeficiente de determinação $\left(R^{2}\right)(1,000)$ foi observado entre 0,500 e $20,0 \mathrm{mg} \mathrm{L}^{-1}$. O limite de detecção (LD) e o limite de quantificação (LQ) do método foram estimados a partir de medidas de 5 replicatas independentes do padrão contendo $0,500 \mathrm{mg} / \mathrm{L}$ de Ivermectina em metanol. ${ }^{12}$ É interessante observar que, os valores de $\operatorname{LD}\left(0,093 \mathrm{mg} \mathrm{L}^{-1}\right)$ e LQ $(0,310$ $\left.\mathrm{mg} \mathrm{L}^{-1}\right)$ indicam que a sensibilidade do método espectrofotométrico é melhor que a necessária para a determinação de Ivermectina nas amostras estudadas, já que as diluições levam a concentrações na faixa de $10 \mathrm{mg} \mathrm{L}^{-1}$.

\section{Determinação espectrofotométrica de Ivermectina em medicamentos}

A etapa seguinte do trabalho consistiu na preparação de diluições 1:1000 de diferentes medicamentos, que foram avaliados em triplicatas independentes (Tabela 4). Os valores esperados para estas determinações eram as concentrações nominais de Ivermectina de todos os medicamentos $(\sim 1 \%)$, conforme declarado em seus rótulos. Entretanto, como é possível verificar a partir da Tabela 4, as concentrações obtidas correspondiam a diferenças de 10 a $200 \%$ em relação às concentrações nominais, indicando alguma interferência na determinação da substância de interesse ou enormes discrepâncias entre a concentração nominal e a concentração obtida ou entre a concentração nominal e a concentração real no medicamento. Para verificar a exatidão dos resultados, o método da adição padrão foi empregado na reavaliação nos medicamentos estudados.
Tabela 4. Concentrações de Ivermectina ( $\%$ p/v) nos medicamentos estudados, determinadas por espectrofotometria de absorção $(\lambda=246 \mathrm{~nm})$ a partir da curva analítica

\begin{tabular}{|c|c|c|c|}
\hline \multirow[b]{2}{*}{ Medicamentos } & \multicolumn{2}{|c|}{ Concentrações obtidas } & \multirow{2}{*}{$\begin{array}{l}\text { Diferença entre o } \\
\text { valor encontrado } \\
\text { e o nominal }(\%)\end{array}$} \\
\hline & $\begin{array}{c}\text { Na solução } \\
\text { diluída }(\mathrm{mg} / \mathrm{L})\end{array}$ & $\begin{array}{c}\text { No medicamento } \\
(\% \mathrm{p} / \mathrm{v})\end{array}$ & \\
\hline \multicolumn{4}{|l|}{ Ampolas } \\
\hline A & $12,98 \pm 0,07$ & $1,30 \pm 0,01$ & 30 \\
\hline $\mathrm{B}$ & $11,66 \pm 0,11$ & $1,17 \pm 0,01$ & 17 \\
\hline $\mathrm{C}$ & $11,02 \pm 0,05$ & $1,10 \pm 0,01$ & 10 \\
\hline $\mathrm{D}$ & $14,57 \pm 0,02$ & $1,46 \pm 0,01$ & 46 \\
\hline \multicolumn{4}{|l|}{ Frascos } \\
\hline $\mathrm{E}$ & $16,48 \pm 0,04$ & $1,65 \pm 0,01$ & 65 \\
\hline $\mathrm{F}$ & $30,07 \pm 0,37$ & $3,01 \pm 0,04$ & 201 \\
\hline G & $30,31 \pm 0,45$ & $3,03 \pm 0,04$ & 203 \\
\hline $\mathrm{H}$ & $14,90 \pm 0,12$ & $1,49 \pm 0,01$ & 49 \\
\hline
\end{tabular}

\section{Determinação espectrofotométrica de Ivermectina em medicamentos pelo método da adição padrão}

Alíquotas de 100, 300 e $600 \mu \mathrm{L}$ de solução de Ivermectina 100 $\mathrm{mg} \mathrm{L}^{-1}$ foram misturadas a $1 \mathrm{~mL}$ das soluções de medicamentos previamente diluídas (100 vezes). Os volumes das soluções foram completados a 10,0 mL, a fim de obter acréscimos de, respectivamente, 10,0; 30,0 e 60,0\% da concentração esperada de Ivermectina na solução final. As curvas de adição padrão apresentaram bons valores de coeficiente de determinação, conforme ilustrado para o medicamento H. Recuperações próximas de $100 \%$ (avaliadas em paralelo com medidas na curva analítica), com coeficientes de variação (CVs) menores que $1 \%$, exceto no caso dos medicamentos $\mathrm{A}$ e B, que apresentaram CVs de 1,4 e $1,3 \%$, respectivamente, foram obtidas. As concentrações de Ivermectina nos medicamentos foram determinadas considerando os fatores de diluição (1000 x) (Tabela 5).

Tabela 5. Concentrações de Ivermectina (\% p/v) nos medicamentos estudados, determinadas por espectrofotométrica através do método de adição padrão

\begin{tabular}{|c|c|c|c|}
\hline \multirow[b]{2}{*}{ Medicamentos } & \multicolumn{2}{|c|}{ Concentrações obtidas } & \multirow{2}{*}{$\begin{array}{l}\text { Diferença entre o } \\
\text { valor encontrado } \\
\text { e o nominal }(\%)\end{array}$} \\
\hline & $\begin{array}{c}\text { Na solução } \\
\text { diluída (mg/L) }\end{array}$ & $\begin{array}{c}\text { No medicamento } \\
(\% \mathrm{p} / \mathrm{v})\end{array}$ & \\
\hline \multicolumn{4}{|l|}{ Ampolas } \\
\hline A & $12,70 \pm 0,34$ & $1,27 \pm 0,03$ & 27 \\
\hline $\mathrm{B}$ & $11,12 \pm 0,23$ & $1,11 \pm 0,02$ & 11 \\
\hline $\mathrm{C}$ & $10,72 \pm 0,11$ & $1,07 \pm 0,01$ & 7 \\
\hline $\mathrm{D}$ & $14,46 \pm 0,12$ & $1,45 \pm 0,01$ & 45 \\
\hline \multicolumn{4}{|l|}{ Frascos } \\
\hline $\mathrm{E}$ & $15,63 \pm 0,03$ & $1,56 \pm 0,01$ & 56 \\
\hline $\mathrm{F}$ & $28,72 \pm 0,22$ & $2,87 \pm 0,02$ & 187 \\
\hline G & $29,45 \pm 0,32$ & $2,94 \pm 0,03$ & 194 \\
\hline $\mathrm{H}$ & $13,84 \pm 0,11$ & $1,38 \pm 0,01$ & 38 \\
\hline
\end{tabular}

O método da adição padrão permitiu obter valores um pouco mais concordantes com o valor esperado, o que indica que, de alguma forma, reduziu possíveis interferências. Assim, considerando os resultados obtidos e a concentração nominal dos medicamentos, no caso do medicamento $\mathrm{C}$ e, talvez, no caso do medicamento $\mathrm{B}$, este 
método poderia ser considerado como capaz de corrigir as interferências. Entretanto e, notadamente, no caso dos medicamentos multidose, isto não ocorreu. De qualquer forma, estes resultados indicaram que o método da adição padrão também podia levar a discrepâncias e era pouco robusto (apenas 1 ou 2 medicamentos em 8 puderam ser analisados por ele). Ademais, possivelmente também era inexato, além de ser trabalhoso e de baixa produtividade. A relativa concordância entre o método da curva analítica e o método da adição padrão também indicava que ambos foram tendenciosos na mesma direção, levando a superestimativas de concentração.

\section{Determinação de Ivermectina em medicamentos por cromatografia líquida de alta eficiência com detecção por UV-DAD}

Uma vez que os resultados apontaram que componentes das soluções dos medicamentos interferiam na determinação do analito por espectrofotometria, ficou praticamente demonstrado que a separação do analito e dos componentes dos medicamentos era necessária, o que levou ao uso de cromatografia líquida de alta eficiência com detecção no UV (CLAE-UV).

\section{Otimização das condições cromatográficas}

Como as amostras continham apenas uma substância de interesse, o principal objetivo da separação cromatográfica era buscar a melhor simetria e o pico mais fino possível, sem coeluição com os excipientes dos medicamentos. Os comprimentos de onda de 238, 246, 254 e $260 \mathrm{~nm}$ foram usados nas avaliações iniciais da separação de Ivermectina da matriz, de modo a se obter uma avaliação de possíveis interferências, mas na sequência deste trabalho nas determinações desta substância por CLAE-UV foi empregado apenas o comprimento de onda de $246 \mathrm{~nm}$.

Fases móveis de diferentes composições, contendo acetonitrila ou metanol, e água ou tampão fosfato $(\mathrm{pH}=3,4)$ foram inicialmente estudadas a fim de otimizar a separação cromatográfica. Foram avaliadas diferentes proporções de solventes e água, modo isocrático e em gradiente e diferentes vazões. Estes dois solventes foram escolhidos devido à boa solubilidade desta substância em ambos. Variando-se as proporções destes dois solventes, em combinação ou não com a água, ficou evidente que, como esperado, com maiores proporções do solvente orgânico na fase móvel, o tempo de retenção da Ivermectina era reduzido.

Metanol foi selecionado para a fase móvel. Foram avaliadas diferentes proporções de metanol e água, resultando no gradiente descrito acima. O tempo de retenção da Ivermectina foi em média 10,4 min. Comparando este valor com o gradiente empregado tornouse evidente que, praticamente após cessar o bombeamento de água, quando restava apenas metanol na fase móvel, a Ivermectina logo era eluída, devido ao seu caráter lipofílico e baixa afinidade com a água.

Os cromatogramas das soluções dos padrões e de diferentes medicamentos, no que tange aos tempos de retenção e ao comportamento cromatográfico, foram bastante semelhantes nestas condições, conforme ilustrado na Figura 3. As condições experimentais permitiram a eluição de apenas um pico com alta simetria e alta pureza de pico $(>99,8 \%)$ o que facilitou a quantificação de Ivermectina nos medicamentos. Conforme mencionado na descrição de reagentes e solventes, os dados de CLAE-EM indicaram tratar-se de apenas uma substância principal.

\section{Determinação de Ivermectina em medicamentos por CLAE-UV}

Soluções padrão de Ivermectina em metanol com concentrações

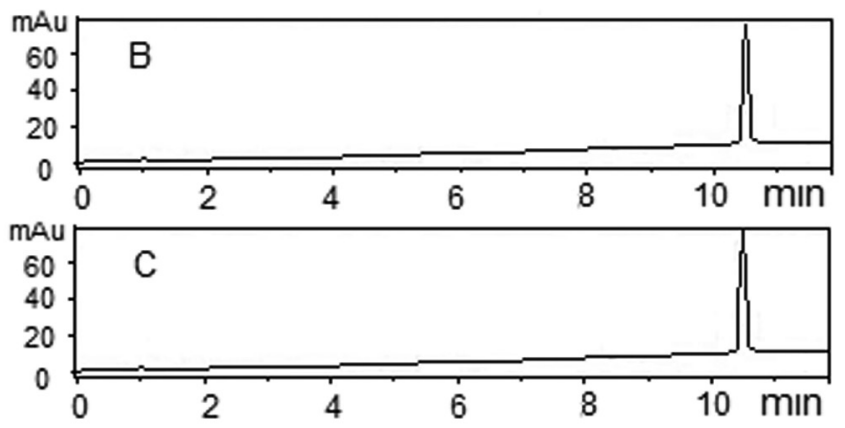

Figura 3. Cromatogramas das soluções de dois medicamentos (B e C) após diluição em metanol

entre 0,500 e 20,0 mg/L foram analisadas em triplicatas independentes e os resultados obtidos foram usados para a construção de curvas analíticas. O limites de detecção (LD) e de quantificação (LQ) do método foram estimados a partir de medidas de 5 replicatas independentes do padrão contendo $0,500 \mathrm{mg} \mathrm{L}^{-1}$ de Ivermectina em metanol. ${ }^{12}$ Os valores de $\operatorname{LD}\left(0,016 \mathrm{mg} \mathrm{L}^{-1}\right)$ e LQ $\left(0,055 \mathrm{mg} \mathrm{L}^{-1}\right)$ indicam que a sensibilidade do método cromatográfico é, do mesmo modo que no caso do método espectrofotométrico, melhor que a necessária para determinação de Ivermectina nas amostras estudadas, já que as diluições levam a concentrações na faixa de $10 \mathrm{mg} \mathrm{L}^{-1}$. Apesar do valor estimado do LQ $\left(0,055 \mathrm{mg} \mathrm{L}^{-1}\right)$, na prática, foi observado que a menor área de pico capaz de ser quantificada pelo método correspondia a $0,170 \mathrm{mg} \mathrm{L}^{-1}$ e este valor foi considerado como LQ do método. Entretanto, como as concentrações das soluções avaliadas neste estudo são muito superiores a este valor, não há nenhum inconveniente analítico neste fato.

A análise das amostras previamente diluídas (1000 vezes), nas condições cromatográficas otimizadas, permitiu estimar as concentrações médias de Ivermectina nos medicamentos estudados, após 3 medidas independentes de cada um dos medicamentos, a partir da curva analítica (Tabela 6).

Foi considerado que a mesma constante aplicada para cálculo das concentrações médias (1000) nos medicamentos se aplicava aos desvios padrões, que poderiam, portanto, ser expressos como na Tabela 6. Para avaliar a concordância entre os resultados obtidos e as concentrações nominais dos medicamentos estudados, o nível de confiança ( $\mathrm{t}$ ) do intervalo de confiança de cada resultado foi calculado do valor médio encontrado e do desvio padrão. ${ }^{12}$

Os dígitos expressos como índices na última coluna da Tabela 6 são não significativos, mas foram mantidos para possibilitar avaliar a concordância destes resultados com o especificado nos rótulos dos produtos, através dos intervalos de confiança (IC). Como a concentração esperada é $1,00 \%$, o valor experimental deveria estar na faixa de $1,00 \% \pm$ IC.

As concentrações dos medicamentos A, B, C, E e H não apresentam diferenças significativas em relação à concentração nominal de Ivermectina (1\%) a nível de significância de 0,95. O mesmo ocorreu para as concentrações medidas nos medicamentos E e G que não apresentam diferenças significativas em relação ao valor esperado a níveis de significância de 0,98 a 0,99, respectivamente. De qualquer forma, todos estes valores estão na faixa de $\pm 10 \%$ da concentração nominal, que é usualmente aceita na produção de certos medicamentos.

O caso do medicamento D é mais complexo, pois a concentração de Ivermectina determinada encontra-se fora da faixa de $\pm 10 \%$ aceita. Outros lotes deste medicamento quando analisados apresentaram comportamento semelhante e acima do rotulado. 
Tabela 6. Concentrações de Ivermectina (\% p/v) determinadas por CLAE-UV nos medicamentos estudados

\begin{tabular}{|c|c|c|c|c|}
\hline \multirow{2}{*}{ Medicamentos } & \multicolumn{2}{|c|}{ Concentrações obtidas } & \multirow{2}{*}{-Intervalo de confiança $(\% \mathrm{p} / \mathrm{v})^{\mathrm{a}}$} & \multirow{2}{*}{$\begin{array}{c}\text { Diferença não significativa a } \\
\text { nível de }\end{array}$} \\
\hline & Na solução diluída (mg/L) & No medicamento $(\% \mathrm{p} / \mathrm{v})$ & & \\
\hline \multicolumn{5}{|l|}{ Ampolas } \\
\hline A & $10,38 \pm 0,21$ & $1,03_{8} \pm 0,02_{1}$ & $0,052_{5}{ }^{a}$ & \\
\hline B & $10,31 \pm 0,17$ & $1,03_{1} \pm 0,01_{7}$ & $0,042_{5}{ }^{a}$ & \\
\hline $\mathrm{C}$ & $10,26 \pm 0,15$ & $1,02_{6} \pm 0,01_{5}$ & $0,037_{5}^{\mathrm{a}}$ & \\
\hline $\mathrm{D}$ & $12,12 \pm 0,40$ & $1,21_{2} \pm 0,04_{0}$ & $0,100_{0}$ & 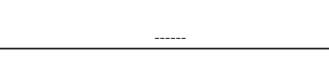 \\
\hline \multicolumn{5}{|l|}{ Frascos } \\
\hline E & $10,65 \pm 0,09$ & $1,06_{5} \pm 0,00_{9}$ & $0,022_{5}$ & 0,99 \\
\hline $\mathrm{F}$ & $10,45 \pm 0,22$ & $1,04_{5} \pm 0,02_{2}$ & $0,055_{0}{ }^{a}$ & \\
\hline G & $10,73 \pm 0,16$ & $1,07_{3} \pm 0,01_{6}$ & $0,040_{0}$ & 0,98 \\
\hline $\mathrm{H}$ & $10,50 \pm 0,21$ & $1,05_{0} \pm 0,01_{7}$ & $0,052_{5}$ & \\
\hline
\end{tabular}

(a) Indica um intervalo de confiança a nível de $95 \%$.

\section{Validação parcial do método de determinação de Ivermectina por HPLC-UV}

Para a validação parcial do método desenvolvido, alguns parâmetros foram avaliados. Estes parâmetros foram avaliados apenas para o método cromatográfico, uma vez que o método espectrométrico, mesmo no caso da adição padrão, apresentava forte tendência de superestimativa.

\section{Avaliação de recuperação}

Embora o método não envolvesse nenhuma etapa adicional de preparação da amostra e os cromatogramas de todas as amostras analisadas fossem semelhantes entre si, foram realizados experimentos de recuperação em dois medicamentos $(\mathrm{C}$ e E), que correspondem a medicamentos em ampola e em frascos multidose.

Foram realizados ensaios de recuperação em três níveis para cada amostra - 10, 30 e 50\% - em triplicatas independentes. As soluções foram preparadas do mesmo modo como descrito para as determinações espectrofotométricas. Os níveis estudados e os resultados obtidos são apresentados na Tabela 7. Como não há produto ou padrão certificado para a avaliação da exatidão do método, a recuperação alta e próxima de $100 \%$ indica que o método apresenta boa exatidão. A distribuição das recuperações em torno do valor esperado de recuperação (100\%) indica que o método não apresenta tendência, pois há valores maiores e menores que $100 \%$, indicando que não há sub- ou superestimativas de resultados.

Tabela 7. Recuperações obtidas para medicamentos de diferentes características (ampola e frasco multidose), em três níveis

\begin{tabular}{lcccc}
\hline \multirow{2}{*}{ Medicamentos } & $10 \%$ & $30 \%$ & $50 \%$ & Média \\
\cline { 2 - 5 } & \multicolumn{4}{l}{ Recuperação (\%) } \\
\hline C (ampola) & 99,3 & 102 & 104 & $\mathbf{1 0 2}$ \\
E (frasco) & 98,2 & 99,7 & 101,4 & $\mathbf{9 9 , 7}$ \\
\hline
\end{tabular}

\section{Avaliação de repetitividade (precisão intracorrida)}

Para avaliar a repetitividade foram utilizados a área média $(13,37)$ e seu desvio padrão $(0,15)$, resultados obtidos para as estimativas do LD e do LQs por CLAE-UV que, por estarem na extremidade da curva analítica, são os que tendem a apresentar maior dispersão. Foi obtido coeficiente de variação de $1,14 \%$, que pode ser considerado relativamente baixo, se for levado em consideração que foi obtido em uma concentração próxima ao LQ. Na curva analítica como um todo, a repetitividade dos resultados foi $\leq 1 \%$ nos outros pontos.

\section{Avaliação da sensibilidade do método}

O coeficiente angular de uma curva analítica define a sensibilidade de um método analítico. $\mathrm{O}$ valor de sensibilidade obtido para o sistema cromatográfico em questão foi de $28,6 \mathrm{~L} \mathrm{mg}^{-1}$. A sensibilidade está relacionada aos meios onde são realizadas as separações cromatográficas e à estrutura da substância estudada.

\section{Comparação dos resultados obtidos por espectrofotometria e CLAE}

Os resultados obtidos pelo método de adição padrão espectrométrico e o método de CLAE estão comparados na Tabela 8.

Tabela 8. Comparação das concentrações de Ivermectina determinadas pelos dois métodos estudados (método espectrofotométrico de adição padrão e CLAE)

\begin{tabular}{cccc}
\hline Medicamentos & $\begin{array}{c}\text { Adição padrão e Calibração externa } \\
\text { espectofotometria } \\
(\% \text { p/v })\end{array}$ & $\begin{array}{c}\text { e CLAE } \\
(\% \mathrm{p} / \mathrm{v})\end{array}$ & $\begin{array}{c}\text { Diferença }(\%) \\
(100 *(\text { Razão }-1))\end{array}$ \\
\hline Ampolas & & & \\
A & $1,27 \pm 0,03$ & $1,04 \pm 0,02$ & $\mathbf{2 2 , 1}$ \\
B & $1,11 \pm 0,02$ & $1,03 \pm 0,02$ & $\mathbf{7 , 8}$ \\
C & $1,07 \pm 0,01$ & $1,03 \pm 0,02$ & $\mathbf{3 , 9}$ \\
D & $1,45 \pm 0,01$ & $1,21 \pm 0,04$ & $\mathbf{1 9 , 9}$ \\
\hline Frascos & & & \\
E & $1,56 \pm 0,01$ & $1,06 \pm 0,01$ & $\mathbf{4 7 , 2}$ \\
F & $2,87 \pm 0,02$ & $1,04 \pm 0,02$ & $\mathbf{1 7 6}$ \\
G & $2,94 \pm 0,03$ & $1,07 \pm 0,02$ & $\mathbf{1 7 5}$ \\
H & $1,38 \pm 0,01$ & $1,05 \pm 0,02$ & $\mathbf{3 1 , 4}$ \\
\hline
\end{tabular}

A comparação dos resultados obtidos pelos dois métodos indica que em alguns casos as diferenças entre os dois métodos são bastante altas. Este fato é mais evidente no caso dos medicamentos de longa ação (apresentados em frascos) que contêm matriz oleosa. Em algumas preparações em ampolas (B e C) as concentrações determinadas pelos dois métodos parecem ser relativamente concordantes, mas a 
aplicação do teste $\mathrm{t}$ indicou que mesmo para o medicamento $\mathrm{C}$, onde os resultados obtidos pelos dois métodos são os mais próximos, as concentrações estimadas são diferentes.

A comparação feita na Tabela 8 reitera a observação anterior que a determinação de Ivermectina nestes medicamentos deve ser realizada por CLAE-UV, já que é necessária a separação cromatográfica do princípio ativo.

\section{CONCLUSÕES}

Os resultados obtidos empregando espectrofotometria de absorção no UV foram tendenciosos e indicaram que era necessário um método capaz de separar ou isolar o princípio ativo. O emprego de cromatografia líquida de alta eficiência (CLAE-UV) se deu por conta desta necessidade.

Com as determinações realizadas em CLAE foi possível otimizar um método obtendo boa separação, empregando solventes de baixo custo, com um tempo de análise que permite cerca de 5 análises por hora, sendo, portanto, aplicável a sistemas de controle de qualidade industrial ou de inspeção.

O método cromatográfico apresentou boa linearidade (pelo menos 2 ordens de grandeza) com excelentes correlações ( $\mathrm{R}>0,999)$, boas recuperações e limites de detecção e quantificação melhores que o necessário para avaliar as amostras de interesse. Estes resultados também indicam que o método desenvolvido pode ser utilizado rotineiramente para controle de qualidade e avaliação de medicamentos farmacêutio-veterinários contendo Ivermectina.

\section{REFERÊNCIAS}

1. http://www.sindan.org.br/sd/informacoes/classe.aspx, acessada em Setembro 2011.

2. Fink, D.; Porras, A. Em Ivermectin and Abamectin; Campbell, W. C., ed.; Springer-Verlag: New York, 1989, p. 90-113.

3. Borges, F. A.; Costa, G. H. N.; Arantes, T. P.; Silva, H. C.; Barbosa, O. F.; Oliveira, G. P.; Costa, A. J.; A Hora Veterinária 2003, 23, 5.

4. Campbell, W. C.; Fisher, M.; Stapley, E.; Albers-Schönberg, G.; Jacob, T.; Science 1983, 221, 823.

5. Spinoza, H. S.; Górniak, S. L.; Bernardi, M. M.; Farmacologia aplicada à medicina veterinária, Guanabara Koogan: Rio de Janeiro, 1996.

6. EMEA - The European Agency for the Evaluation of Medicinal Products; Veterinary medicines evaluation unit, http://www.emea.eu.int/pdfs/ vet/mrls/, acessada em Setembro 2011.

7. Kolberg, D. I. S.; Presta, M. A.; Wickert, C.; Adaime, M. B.; Zanella, R.; J. Braz. Chem. Soc. 2009, 20, 1220.

8. CPVS - Compêndio de Produtos Veterinários - SINDAN; http://www. cpvs.com.br/cpvs/index.html, acessada em Outubro 2010.

9. Gárcia-Mayor, M. A.; Garcinuño, R. M.; Fernández-Hernando, P.; Durand-Alegría, J. S.; J. Chromatogr., A 2006, 1122, 76.

10. Kees, F.; Spangler, S.; Wellenhofer, M.; J. Chromatogr., A 1998, 812, 287.

11. Yang, S.; Carlson, K. H.; J. Chromatogr., A 2004, 1003, 21.

12. Ramos, G. R.; Álvarez-Coque, M. C. G.; Quimiometria, Editorial Sintesis: Madrid, 2001. 